\title{
La herencia clásica como instrumento para comprender a Dios. Clemente de Alejandría, Stromata V $(89,1-100,4)^{*}$
}

\author{
Claudio César Calabrese ${ }^{a}$ \\ Universidad Panamericana, México \\ http://orcid.org/0000-0001-9844-3368
}

RECIBIDO: 20-07-19. APROBADO: 02-10-19

Resumen: Desde un enfoque interpretativo presentamos los resultados de lectura de Stromata $V(89,1-100,4)$ de Clemente de Alejandría, en orden a considerar la herencia clásica como instrumento para profundizar la comprensión de Dios. Nos interesa mostrar la correlación entre la secuencia griega-judía y los textos bíblicos y, al mismo tiempo, plantear la continuidad, no exenta de dificultades, entre la peculiar noción de lo divino de la tradición helénica y la concepción increada de naturaleza, que implica la paulatina identificación de las nociones griegas de physis y theós. Según el método de lectura de Clemente, hacemos el análisis de los textos griegos esclarecidos a partir del Antiguo Testamento y viceversa, para concluir en su convicción personal -en el marco del cristianismo primitivo- de que los cristianos son herederos de toda apertura de Dios al mundo. Para alcanzar esta conclusión, Clemente argumenta, en sede platónica, desde una perspectiva a la vez antropológica (el hombre puede asimilarse a Dios progresivamente, a partir de su disposición natural a la vida virtuosa) y cristológica ("todo proviene del único Maestro"). Por ello, en la interpretación de nuestro autor, la revelación ha resignificado la historia humana también desde una perspectiva metafísica, pues Cristo ha incorporado la humanidad a la historia, en un sentido completamente nuevo, en cuanto fundamenta providencialmente la cultura pagana. En la perspectiva de Stromata, esto es posible porque desde el origen se manifiesta un modo artístico de interpretar al hombre en su relación con la divinidad: el saber mítico y filosófico de los griegos sobre Dios había sido, por ello mismo, también teológico, en cuanto resultaba manifiesto en el cosmos. Este modelo hermenéutico se mostrará, desde el comienzo, en revisión y en crisis, porque la persona de Cristo podrá quedar oculta, desde la perspectiva de nuestro entendimiento, por la necesaria referencia cósmica.

Palabras clave: Antigüedad tardía; cristianismo primitivo; Clemente de Alejandría; fe; revelación; providencia; recepción de la herencia clásica; filosofía; mito; cosmos.

*Artículo de reflexión.

${ }^{a}$ Autor de correspondencia. Correo electrónico: ccalabrese@up.edu.mx 


\section{The Appropriation of the Classical Inheritance as an Instrument to}

Understand God. Clement of Alexandria, Stromata V $(89,1-100,4)$

AвsTRACT: From an interpretative approach, we present the reading results of Stromata $V$ $(89,1-100,4)$ of Clement of Alexandria, in order to consider classical inheritance as an instrument to deepen understanding of God. We are interested in showing the correlation between the Greek-Jewish sequence and the biblical texts, and at the same time, to propose continuity - not without difficulties - between the peculiar notion of the divine of the Hellenic tradition and the uncreated conception of nature, which implies the gradual identification of the Greek notions of physis and theós. According to Clemente's method of reading, we make the analysis of the Greek texts clarified from the Old Testament and vice versa, to conclude in his personal conviction, within the framework of primitive Christianity, that Christians are heirs of all openness of God to the world. To reach this conclusion, Clemente argues, from a Platonic perspective, with a view that is both anthropological (man can progressively assimilate to God, from his natural disposition to the virtuous life) and Christological ("everything comes from the only Master"). For this reason, in the interpretation of our author, revelation has redefined human history also from a metaphysical perspective, since Christ has incorporated humanity into history, in a completely new sense, as he providentially founds pagan culture. In Stromata, this is possible, because from the beginning, an artistic way of interpreting man in his relationship with divinity is manifested: the mythical and philosophical knowledge of the Greeks about God had been, for this reason, also theological, insofar as it was manifest in the cosmos. This hermeneutical model will be shown, from the beginning, in revision and in crisis, because the person of Christ may be hidden, from the perspective of our understanding, by the necessary cosmic reference.

Key Words: Late antiquity; early Christianity; Clement of Alexandria; Faith; Revelation; Providence; Reception of classical heritage; Philosophy; Myth; Cosmos.

\section{Cómo CITAR:}

Calabrese, Claudio César. "La herencia clásica como instrumento para comprender a Dios. Clemente de Alejandría, Stromata V (89,1-100,4)". Theologica Xaveriana (2021): 1-26. https://doi.org/10.11144/javeriana.tx71.hcicd 


\section{Introducción}

La hipótesis que planteamos en nuestro artículo pone a consideración que Clemente de Alejandría, a partir de su modelo cristocéntrico de exégesis del Antiguo Testamento y de la cultura clásica, con las peculiaridades que distinguen a ambas lecturas, profética y alegórica respectivamente, expresa su personalísima convicción de que el cristianismo es heredero de toda apertura de Dios al mundo, es decir, de toda referencia al Absoluto.

Según esta persuasión se manifiesta, desde el origen, cierto modo de interpretar al hombre en su relación con lo divino, pues el saber mítico y filosófico de los griegos había sido también teológico, en cuanto Dios resultaba manifiesto en el cosmos. Por ello, con Clemente de Alejandría observamos ya la grandeza problemática de toda teología: ningún recurso intelectual le es ajeno al momento de especular acerca del misterio de la fe.

En Stromata V, 89,1-100,4, Clemente plantea gradualmente los alcances de la revelación dada a Moisés y la noción de Dios creador; en el desarrollo puntual del tema de la creación se presenta una explicación de la materia, siempre en el doble lineamiento griego (en la perspectiva platónico-estoica y como expoliación mosaica') y bíblico (preferentemente con citas del Antiguo Testamento), así como del surgimiento del ser humano "a imagen y semejanza" de Dios.

En este punto, la argumentación clementina descansa en la consideración platónica del hombre que progresivamente se asimila a $\operatorname{Dios}^{2}$ y en su consecuencia: el significado del hombre bueno y de su relación con el resto de la sociedad; la relectura que realiza Clemente de la referencia platónica a la correlación entre la nobleza de los metales y la disposición para la vida virtuosa de los hombres implica una revisión de los temas planteados hasta aquí, la cual culmina con una rápida presentación del mito de Prometeo, en citas de Calímaco y Hesíodo.

Consideramos que la escueta referencia a la figura del titán y de Pandora, tan alentadora como conflictiva en una lectura cristiana, concentra el modo como Clemente comprende el mundo clásico pues aquí, en clave mítica, no aplica de manera necesaria y directa el recurso del plagio. Debido a lo anterior, nos proponemos demostrar que Clemente realiza una lectura cristológica para comprender el legado

${ }^{1}$ Clemente de Alejandría, Stromata IV-V, Libro V, 92,1. Tenemos en cuenta dos ediciones: (1) Clemente de Alejandría, Stromata IV-V (Madrid-México-Bs.As.: Ciudad Nueva, 2003. Introducción, traducción y notas de Marcelo Merino Rodríguez). Y (2) para consultas puntuales, Clément d'Alexandrie, Les Stromates, Stromate V, (Paris: Éditions du Cerf, 1981, Tome 1: Introduction, Texte Critique et Index par A. le Boulluec; Traduction par P. Voulet; SChr. 298).

${ }^{2}$ Clemente de Alejandría, Stromata IV-V, Libro V, 95, 1. 
de la cultura humana ("todo proviene del único Maestro"), en conjunción con una cita de Platón (Rep 415), que resulta clave para comprender el procedimiento intelectual de Stromata.

El método clementino de confirmar una afirmación que se considera de importancia mediante la autoridad de los antiguos, en especial de los poetas, se encuentra en el corazón de la tradición griega. Sin embargo, únicamente a partir de los estoicos se transformará en el modo habitual de sostener y confirmar una idea; Cicerón toma a broma la exageración de este recurso en De natura Deorum (I, 14,36), por boca del epicúreo Valerio, quien señala que los estoicos hacen que los poetas afirmen lo que nunca pensaron.

Durante la difusión y consolidación del cristianismo, en el encabalgamiento de los siglos II y III, Plutarco y los representantes de la segunda sofística afirman de manera definitiva este modo de leer y de escribir, que busca sostenerse en los antiguos ${ }^{3}$. Dicho modelo fue seguido de manera natural por los apologistas cristianos, que no solo se ocupan de la verdad del mensaje, sino también de darle continuidad en la cultura pagana, en el sentido -como veremos adelante- de que todas las verdades provienen del Logos o Maestro. Por ello, Clemente considera que no debe servirse únicamente de la Biblia, sino también de la cultura de su época; en correspondencia con este espíritu leemos que el título, Stromata, y especialmente el modelo compositivo de su obra, se sustentan en una cita de Sófocles:

Había un vellón de lana, era una libación sagrada del jugo de la vid y el racimo preciosamente guardado; había también diversos frutos mezclados con granos de cebada y de copioso aceite, además de la variopinta obra plasmada de cera de la rubia abeja. ${ }^{4}$

Se trata de la reunión de elementos diversos que buscan un encuentro con la verdad; como la abeja liba aquí y allá, Clemente va de un autor a otro, entre griegos y bíblicos, para tejer un tapiz nuevo, en el que se refleje la variedad de la unidad.

Esta actitud delimita la primera fase de su interpretación: una cita textual es un homenaje de la posteridad a un poeta o a un filósofo que tiene "algo que decir" a su presente; tal homenaje implica, sin embargo, que un verso o un fragmento concretos han sido arrancados de su entretejido vital y han quedado aislados con el valor de una sentencia. Pierde relevancia su significado original, pues toma una dirección desconocida, en cuanto dialoga con un contexto completamente nuevos.

\footnotetext{
${ }^{3}$ Moreschini, Storia del pensiero cristiano tardo-Antico, 157-163.

${ }^{4}$ Sófocles, Fragm. 366, en Clemente de Alejandría, Stromata IV-V, Libro IV, 6,2.

${ }^{5}$ Calabrese, "Literatura y teología en el Libro X de La ciudad de Dios", 69-88.
} 
¿Qué significa la trascendencia de Dios creador en cada caso? La religión clásica -tenemos presente las tensiones que esta expresión implica- la consideró en términos espaciales: un "aquî" y un "más allä" que se encuentra siempre disponible; la fe cristiana, en términos temporales, como un "presente ilimitado" y un "sucederse de momentos": un actuar de Dios que no puede disolverse en consideraciones metafísicas, es decir, lo que nunca está completamente a "disposición del hombre”. El mensaje salvífico de Cristo se concibe, entonces, en clave temporal.

Nuestro método de trabajo es hermenéutico, es decir, un método de explicación y exposición de textos; si toda cultura implica una interpretación, una consideración de esta naturaleza contiene una reflexión expositiva sobre la tradición a la que pertenece. La incorporación de la cultura clásica como recurso privilegiado para la interpretación del dato revelado es un procedimiento intelectual complejo que implica, por un lado, confrontar los universos propios de cada corpus textual -griego y bíblico- y, por otro, aceptar la perspectiva cristiana de quien hace la selección y manifiesta su voluntad de comprender a la luz de la tradición helénica.

Por ello, el aporte de la generación de teólogos del siglo II fue presentar la noción de Dios como contenido fundamental de la revelación, profundizándolo a la luz de la metafísica. Esta afirmación no debe ocultar las graves dificultades que se presentaron, pues el intento de enriquecer la comprensión del Dios de la Escritura mediante conceptos cosecha-como sabemos- profundos rechazos. En el contexto de la época mencionada, la tarea implica una doble polémica: (1) justificar la novedad cristiana ante los paganos, colocando el énfasis en la continuidad cultural; y (2) tomar distancia de un movimiento extraordinariamente complejo, que agrupamos bajo la denominación de gnosticismo.

Nuestro artículo se ubica de lleno en el punto 1 de dicha polémica, pues nos centraremos en la argumentación sobre la continuidad entre cultura clásica y cristianismo aplicada a la inteligibilidad de Dios. Antes de avanzar, es necesaria la siguiente precisión, que ampliamos en el apartado “QQué significa theós?”. El mundo helenísticoromano fue ajeno a una idea trascendente de lo divino, en el sentido que la expresión conlleva en la tradición judeo-cristiana; su comprensión es completamente inmanente a la noción de physis (conjunto y norma de lo que existe, en sentido ontológico y ético), tanto que lo divino no puede ser comprendido fuera de ella, es decir, que "grados de lo divino" y "grados de inteligibilidad" se corresponden hasta alcanzar la sinonimia.

Resulta importante insistir, al final de este apartado, en que la mitología griega no reconoce un dios que haya tenido la responsabilidad de crear el mundo; la obra hesiódica, por ejemplo, está constituida por una sucesión de epifanías, en las 
que aparecen aspectos divinos del cosmos, que constituyen fases de su fundamento; por ello, es más conveniente denominarlo "fundación" que "creación”.

Una generación previa a Orígenes, es decir, hacia 150, ubicamos el nacimiento de Clemente de Alejandría, presumiblemente en Atenas; también se cree que estudió en la ciudad que quedó indisolublemente ligada a su nombre, tanto en las escuelas públicas cuanto cristianas, lo que explica sus variados conocimientos de literatura y filosofía griegas ${ }^{7}$. El interés por este escritor polifacético y contradictorio ${ }^{8}$ radica, en la perspectiva del presente artículo, en que recurrió a los modelos hermenéuticos del helenismo para comprender más a fondo los textos de la revelación, sin que ello incluyera el rechazo o impugnación necesaria de los mitos griegos?. De esta audacia intelectual nace su presentación del cristianismo como filosofía: fue su modo de hacer "apología" del dogma contra los ataques paganos. Con palabras de Marcelo Merino Rodríguez, el alejandrino retoma los materiales griegos con la clara intención de construir un nuevo edificio, que hemos llamado "filosofía cristiana" ${ }^{10}$.

Estos son los pasos de nuestro recorrido: (1) presentar el contexto cultural de Clemente; (2) considerar el significado del término theós en la cultura helenística; (3) entender la estructura y el contenido de Stromata V; (4) en el contexto anterior, pensar la cultura clásica como recurso para ampliar la comprensibilidad de Dios.

\section{El contexto cultural de Clemente}

Para comprender la relación de Clemente de Alejandría con la cultura de su época es importante recordar que paganos y cristianos compartieron su formación: fueron a las mismas escuelas, tuvieron los mismos maestros, leyeron los mismos libros. Hasta el siglo IV, los maestros fueron invariablemente paganos; lentamente y como consecuencia del edicto de Milán del 313, los cristianos tuvieron acceso a plazas en establecimientos públicos ${ }^{11}$.

Tendremos que esperar hasta los siglos V y VI para observar una educación estatal y cristiana, cuando el conjunto del paganismo quedó fuera de la ley; en medio

${ }^{6}$ Kerényi, Imágenes primigenias de la religión griega. IV. Prometeo. Interpretación griega de la existencia bumana, 41-42.

7 Fiska Hägg, Clement of Alexandria and the Beginnings of Christian Apophanticism, 51-70.

${ }^{8}$ Klibengajtis, "Die Wahrheitsbezeichnungen des Clemens von Alexandrien in ihrem philosophischen und theologischen Kontext”, 316-331.

9 Dawson, Allegorical Readers and Cultural Revision in Ancient Alexandria, 199-205.

${ }^{10}$ Merino Rodríguez, "Clemente de Alejandría, un filósofo cristiano”, 810.

${ }^{11}$ Marrou, Historia de la educación en la Antigüedad, 133-135. 
de tan profundos cambios, el currículo, sin embargo, permaneció sin modificaciones sustanciales, manteniéndose la lectura de las obras paganas. Queda claro que los estudiantes interesados debían completar su formación bíblica en la sinagoga o en la iglesia; en la Edad Media, los estudiantes cristianos de Oriente siguieron leyendo a Homero, y los de Occidente, a Virgilio.

La continuidad de los estudios filosóficos siguió un camino más complejo. El Timeo de Platón puso en escena una divinidad que buscó compartir su felicidad $(29 \mathrm{~d}-30 \mathrm{a})^{12} \mathrm{y}$, al hacerlo, hizo un mundo tan perfecto cuanto fue posible; principalmente en el Fedón nos legó también la noción de la inmortalidad del alma (114c-d) ${ }^{13}$.

Los cristianos recibieron y comprendieron esta noción a partir del dogma central de la resurrección de los cuerpos, con lo cual la espiritualizaron por completo. En la misma filosofía ambiente, los cristianos sintieron una fuerte proximidad con los estoicos, especialmente en lo que se refiere a la virtud, al entenderla como el bien más elevado. Señala Boys-Stone ${ }^{14}$ que la sintonía entre las tradiciones paganas y judeocristianas dio lugar a lo que denomina "mito histórico": la idea de que una sabiduría primitiva se dispersó por el mundo y de que consecuentemente verdades antiguas quedaron ocultas bajo el ropaje del mito.

Si esto es así, el conjunto de la cultura clásica no se forjó en el esfuerzo sostenido por encontrar nuevas ideas, sino a partir de los fragmentos de aquella sabiduría arcaica $^{15}$. Que se haya originado en Egipto es algo sobre lo que estuvieron de acuerdo los intelectuales paganos, judíos y cristianos; en este punto, sin embargo, el mito se bifurcó en dos caminos narrativos: por un lado, los griegos consideraron que la sabiduría que se puede trazar entre Pitágoras y Platón tuvo su origen en Egipto, como mencionamos; por otro, la tradición judeo-cristiana se tuvo también a sí misma como originaria de la misma geografía, pero con raíces más antiguas; Clemente de Alejandría argumenta que Moisés concentra la doble herencia constituida por la revelación de Dios y las diversas doctrinas de los egipcios, y que Pitágoras y Platón desplegaron lo que conocieron indirectamente de Moisés ${ }^{16}$.

La idea descansa en un único principio: la mayor antigüedad de una doctrina asegura una compenetración más profunda con el estado más primitivo, que aquí

${ }^{12}$ Junco, "La sabiduría moral: entre Eurípides y Sócrates", 53.

${ }^{13}$ Osborn, The Emergence of Christian Theology, 307-313.

${ }^{14}$ Boys-Stones, Post-Hellenistic Philosophy: A Study of its Development from the Stoics to Origen, 99-122.

${ }^{15}$ Herren, The Anatomy of Myth. The Art of Interpretation from the Presocratics to the Church Fathers, 109-111.

${ }^{16}$ Boys-Stones, Post-Hellenistic Philosophy: A Study of its Development from the Stoics to Origen, 176-202. Acusaciones judeo-cristianas contra los griegos de plagiar la tradición mosaica. 
significa simplemente "más perfecto", en que el logos estaba presente en la humanidad de manera prístina ${ }^{17}$.

En este sentido -fundamental para nuestro tema-, Platón expresó la posesión incuestionable de ideas que hicieron que sus diálogos, entendidos adecuadamente, transmitieran aquellas verdades; este "algo más" consiste en descubrir que el rasgo distintivo de dicha verdad fue cumplir con el desafío de interpretar con la mayor fidelidad y agudeza esa cultura primordial y apropiarse de sus rasgos esenciales ${ }^{18}$.

Al tiempo es importante tener presente que en la época de Clemente se produce un giro que cambia la dirección del "platonismo", pues comienza la transición desde la fase medioplatónica hacia el neoplatonismo propiamente dicho, a partir de la obra de Numenio de Apamea (siglo II d. C.), a quien el propio Porfirio cita como influencia; no menos importante resulta advertir que la ciudad de Alejandría fue el centro intelectual donde se inició esta transformación, debido a la labor docente de Ammonio Saccas ${ }^{19}$.

Para que la lectura cristológica de Clemente sea universalizable desde el punto de vista hermenéutico, es necesario establecer los principios de la lectura alegórica, en la perspectiva del mundo helenístico-romano; en él, la tradición alegórica se encuentra fuertemente arraigada, tanto como relectura latina de mitos griegos cuanto como material que permite atizar la reflexión filosófica.

De este modo, lo que conocemos como "alegoría de la caverna" o los mitos platónicos resultan una interpretación de aquella sabiduría, que en la perspectiva de Platón se ha perdido en su conjunto y solo quedan "relatos de los antepasados". El banquete constituye un ejemplo adecuado de este modo de concebir la sabiduría y lo que se dice acerca del pasado del hombre, quien antiguamente tenía su ser pleno (189c): poseía la forma de la esfera, que para los antiguos era sinónimo de perfección.

En la actualidad, por el contrario, el hombre se define por aquella pérdida (190e; 193d); desde esta perspectiva, señalamos que la filosofía platónica está constituida también por el esfuerzo de interpretar lo que para el autor es una tradición sagrada, y en este contexto abre el camino para el modo de leer y de escribir que entraña la alegoría, a pesar de sus reservas, como veremos adelante ${ }^{20}$.

\footnotetext{
${ }^{17}$ Ruíz Aldaz, El concepto de Dios en la teología del siglo II, 17-26.

${ }^{18}$ Havrda, "Some Observations on Clement of Alexandria, Stromata, Book Five", 1-30; Klibengajtis, "Die Wahrheitsbezeichnungen des Clemens von Alexandrien in ihrem philosophischen und theologischen Kontext", 316-331.

${ }^{19}$ Remes, Neoplatonism, 5-6; Ramelli, "Origen and the Platonic Tradition”, 6-8.

${ }^{20}$ Osborne, "Clement of Alexandria”, I, 270-282.
} 
El término "alegoría" designa un método para comprender adecuadamente a Homero y se transformó en un modo de establecer la comprensión profunda del Antiguo Testamento a partir de la figura de Cristo; la llamada "interpretación alegórica" se afianzó como un tipo de exégesis empeñado en descubrir un sentido más allá del literal, aunque eche raíces en él.

Entender los textos literarios en un sentido diverso del literal, considerando las

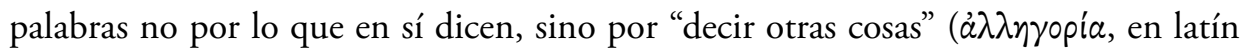
alia oratio) es procedimiento conocido y practicado desde los comienzos de la literatura griega ${ }^{21}$. Como ya mencionamos, un modo de leer se vincula indisolublemente a un modo de escribir, dando lugar a una literatura deliberadamente alegórica. Una aproximación a este proceso nos pone necesariamente en estrecha relación con el mundo complejo del símbolo ${ }^{22}$.

En esta aproximación al mito anotamos que Platón no considera la práctica de la alegoría como método adecuado para profundizar la comprensión del mito. En La República (378d), en el marco de la reflexión acerca de "lo que se debe decir" y "cómo se lo debe decir", el legislador pone de manifiesto dicha negativa: las personas podrían considerar que todos los autores componen alegóricamente, lo que volvería obligatorio desterrar el sentido literal. En términos de pedagogía platónica, no es conveniente enseñar literatura de esta manera a los niños, pues ellos siempre comprenden literalmente.

Platón específicamente entiende la alegoría (el término que utiliza es hypónoia, que significa "pensamiento que se encuentra debajo") como modo de interpretar los mitos en perspectiva filosófica. Por ello, una forma de comprenderlo es seguir sus modelos para significar la mente, el alma y las actividades psíquicas; así, por ejemplo, en el Fedro (246a-249d), el alma es representada por un carro conducido por un auriga, que debe luchar por controlar dos caballos alados que pujan por conducir al carro en direcciones encontradas (arriba-abajo).

Los mitos pertenecen a tradiciones y géneros distintos, y por ello no son idénticos en su dispositivo. Comparten, sin embargo, un elemento común que se percibe con claridad: no pueden ser comprendidos de manera literal, y las historias son verdaderas si se entienden sus mecanismos de composición. Estudiar el modo como la filosofía o la literatura interpretan o reinterpretan los mitos implica realizar

${ }^{21}$ Pfeiffer, History of Classical Scholarship from the Beginnings to the End of the Hellenistic Age, 10-11; 35. Los neoplatónicos lo adoptaron, influencia estoica mediante, como un método de apropiación de la mitología para el discurso filosófico.

${ }^{22}$ Stefaniw, "Allegorical Exegesis in Late Antique Alexandria", 231-251. 
una historia de la cultura clásica y de cómo esta, fusionada con el cristianismo, se prolonga en la Edad Media como alegoría.

En ese sentido distinguimos la interpretación clásica de la cristiana que comienza a cristalizarse como alegoría, en cuanto también toma distancia de los relatos míticos, intentando la adaptación cultural de esos relatos. En Clemente de Alejandría comienza a manifestarse este fenómeno con fuerza y, debido a ello, concordamos con Struck en que la alegoría es, ante todo, un fenómeno de lectura fundado en la autoridad del texto interpretado ${ }^{23}$. Aunque se trata de una lectura que considera al texto expresión de una estructura profunda del cosmos, tal crítica literaria descansa en la interpretación de textos ya existentes.

Ciertamente no se trata de ubicar a la alegoría en el campo literario como perspectiva única, ya que ella se encuentra inmersa en la profundidad de la vida de la cultura y experimenta los cambios y transformaciones que son propias de la historia ${ }^{24}$. Con el afianzamiento de la interpretación de cuño neoplatónico, especialmente con Macrobio $^{25}$, casi dos siglos posterior a Clemente, la frontera entre filosofía y literatura se esfuma, encaminando su esfuerzo exegético al núcleo mítico, como ya aparece con claridad en el propio Platón (Tim 22 c-d; Phaed 69c).

Si con la alegoría se trata de alcanzar un significado que no resulta inmediatamente accesible, entonces se ponen de manifiesto dos aspectos centrales para nuestra investigación: (1) la exigencia de interpretar el texto de modo que ponga en evidencia el contenido de verdad que a priori se considera que contiene; y (2) las transformaciones histórico-culturales requieren de un ejercicio de interpretación permanente, porque sus claves varían con dichos cambios. Si bien -como señalamos en su momentola tradición alegórica se encuentra en el corazón de la tradición greco-latina, observamos el modo como Clemente la dirige a la comprensión filosófica y teológica de la propia cultura y del mensaje salvífico del cristianismo ${ }^{26}$.

\section{¿Qué significa theós?}

Para probar nuestra hipótesis de trabajo es necesario considerar que el tránsito de la concepción de un principio divino intramundano a la de un Dios personal y

\footnotetext{
${ }^{23}$ Struck, Birth of the Symbol. Ancient Readers at the Limits of Their Texts, 3.

${ }^{24}$ Ver a Lamberton, Homer the Theologian: Neoplatonist Allegorical Reading and the Growth of the Epic Tradition.

${ }^{25}$ Setaioli, "Interpretazioni stoiche ed epicuree in Servio e la tradizione dell'esegesi filosofica del mito e dei poeti a Roma (Comuto, Seneca, Filodemo)", 3-46.

${ }^{26}$ Solano Pinzón, "Gregorio de Nisa y el ejercicio de inculturación de la teología”, 512-513.
} 
creador no estuvo exenta de dificultades, cuya gravedad hacía parecer imposible que la herencia clásica pudiese fungir de instrumento en la comprensión de Dios. Con la expresión "principio divino" buscamos interpretar el término griego theós y presentar sus características esenciales; de este modo, se podrá apreciar con más claridad el genio teológico y la intrepidez intelectual de Clemente, así como las razones que nos impiden extrapolar su posición al conjunto del cristianismo antiguo.

En esta perspectiva de análisis, la noción de "lo divino" ordena el punto de interpretación de las realidades sagradas, que a su vez resulta inescindible de la physis o naturaleza, dado el radical sentido inmanente de la cultura clásica. La máxima de Tales de Mileto, según la cual "todas las cosas están llenas de dioses" ${ }^{27}$ se transforma hasta llegar a las distintas formulaciones del agnosticismo sofista del siglo V, que podría presentarse en estos términos: si los dioses existen, se encuentran ellos mismos limitados por la necesidad de la naturaleza; las nociones de "lo divino" y de physis se van fusionando hasta hacerse interdependientes, desde el punto de vista de su comprensión. La tradición cosmológica, hasta Demócrito al menos, considera que la naturaleza es increada: siempre existió y siempre existirá, pues por debajo de los cambios permanece el arkhé, el primer principio, que contiene las causas inherentes del ser y del movimiento.

Así, por ejemplo, Heráclito afirmó que ni dioses ni hombres crearon el universo, sino que es, fue y será fuego ${ }^{28}$. Por irónico que le pueda resultar a nuestra mentalidad, el pensamiento cosmológico se encuentra en íntima vinculación con los mitos del beocio Hesíodo, quien afirma que las cosas primordiales, vacío y tierra (Khaos y Gaia), estaban en el ser desde el principio (generados no generadores) ${ }^{29}$; el resto simplemente acontece, pues nada puso al universo en movimiento.

En este punto resulta necesario considerar que la superioridad de los dioses sobre los hombres se presenta en todos los campos y, con especial agudeza, en el conocimiento; esta distancia ontológica se verifica en que los relatos sobre los dioses son siempre aproximativos y en que las decisiones humanas dependen de la voluntad divina. Como advierte Snell, en el contexto de la cultura homérica y de buena parte de la filosofía cosmológica, el conocimiento de los dioses llega a los seres humanos en términos de inspiración: la invocación a las musas en las aperturas de La Ilíada y de La Odisea sostiene con fuerza esta tesis; allí, en efecto, se observa la oposición entre el saber de los dioses y la necedad humana.

\footnotetext{
${ }^{27}$ Diels y Kranz, Die Fragmente der Vorsokratiker. Fr. 11 a.

${ }^{28}$ Ibíd., Fr. 30.

${ }^{29}$ Hesiod, Theogony, vv. 105-107.
} 
Hacia el 500, Jenófanes (fr. 34), que usualmente difiere del conjunto de la tradición homérica, aquí concuerda, al señalar que el hombre jamás alcanzará un conocimiento que se aproxime al que poseen los dioses, pues la apariencia confunde su comprensión de las cosas; además, los hombres, en cuanto han visto poco, saben poco; tales conceptos nos llevan a la oposición entre saber confiable y ambiguo ${ }^{30}$.

En este punto damos un paso más, en dirección directa al mito de Prometeo, con el que cerramos nuestro seguimiento de las citas de Clemente; para los filósofos o teólogos cristianos hay en este mito una intuición poderosa: el titán que se ofrenda a los hombres representa una prefiguración de Cristo; ellos colocan en el centro de su interpretación la piedad y la comprensión de Prometeo ${ }^{31}$. Ciertamente, esta no era la visión común, sino la de intelectuales relativamente contemporáneos entre sí, como Justino, el propio Clemente, Orígenes y Lactancio; en efecto, el titán también representa la revuelta contra Zeus, mediante el robo del fuego.

A pesar de esta fisonomía ambivalente, prima -entre los primeros cristianos- su aspecto de justo sufriente, que llama la atención en su literalidad: el vínculo entre Prometeo y Cristo, mediante el valor del sacrificio en favor de la humanidad y la creación de los seres humanos desde el fango, tal como se presenta en algunas variantes del relato mítico ${ }^{32}$.

\section{Stromata $V$}

La traducción usual de Stromata es "tapices". El término hace referencia a todo lo que se extiende y cubre una superficie; por analogía se refiere a todo lo que se pone en el suelo como soporte (incluso los pilares de un puente de madera). Su significado más extendido es "colcha", pero también "alfombra", "cama" y "manta" ${ }^{33}$. Por lo anterior consideramos que el título Stromata es una invitación a familiarizarnos con la novedad del encuentro de culturas.

Sin duda, es el comienzo de un modo de organizar los saberes a partir de la revelación. Filón, fiel a su formación platónica, identifica las ciencias (geometría, música, gramática y retórica) con la esclava egipcia Agar, con quien se uniría Abraham (Ismael fue su descendiente), pues su esposa Sara era estéril; de este modo, en la concepción

\footnotetext{
${ }^{30}$ Snell, Die Entdeckung des Geistes. Studien zur Entstehung des europäischen Denkens bei den Griechen, 127-138.

${ }^{31}$ Trousson, Le thème de Prométhée dans la littérature européenne, 91-92.

${ }^{32}$ Duchemin, "Le mythe de Prométhée à travers les âges", 39-72.

${ }^{33}$ Bailly, Dictionnaire Grec-Français, s.v.
} 
filoniana, los saberes de la ciencia quedan subordinados a la filosofía, a su vez subalternada a la sabiduría o revelación de Dios, comunicada por Moisés ${ }^{34}$.

Este problema se encontraba en el corazón del tiempo de Clemente ${ }^{35}$, y, en cuanto tal se presenta en cada época que afronta el tema de la ordenación de los saberes, es decir, cómo subalternar entre sí cada una de las partes en que se articula el conocimiento. Desde el punto de vista teórico se trata de encontrar el principio de unidad entre los diversos momentos de la especulación. Este intenso debate acaeció también en el interior de la cultura greco-latina, particularmente entre los estoicos, quienes ponían en el centro de su atención el problema ético y se preguntaban cómo ordenar el resto de la filosofía, especialmente la física ${ }^{36}$. También Lucio A. Séneca, siguiendo la distinción de Eudoro de Alejandría (fl. 25 a. C.) y más explícitamente de Posidonio (135-51 a. C.), se refirió a los principios de la filosofía teórica, los que están representados en la física, antes de tratar de la ética y de sus desarrollos prácticos ${ }^{37}$.

Cuando aplicamos este esquema a los Stromata encontramos un contorno nuevo: en los tapices, la filosofía griega ha quedado reducida a su concreción discursiva, pues el cristianismo se presenta como la verdadera filosofía (único saber y único modo de vida válidos). Esta "verdadera filosofía" hace propio el saber neoplatónico que, luego de Clemente y Orígenes, constituirá la herramienta del saber teológico ${ }^{38}$.

En Stromata V, Clemente retoma el tratamiento del tema de la fe, luego de haber presentado, en los últimos capítulos de Stromata IV, al perfecto gnóstico, es decir, al mártir. Con el trasfondo de la polémica contra Valentín y Marción, el alejandrino señala que gnosis y fe se requieren mutuamente, al modo que el Padre y el Hijo no pueden comprenderse de manera separada: desde la fe se va a la gnosis ${ }^{39}$.

${ }^{34}$ Philon d'Alexandrie, De congressu eruditionis gratia, c. 11, 79-80.

${ }^{35}$ Clemente de Alejandría, Stromata I, 28-32; Van Den Hoek, Clement of Alexandria and his Use of Philo in the "Stromateis". An Early Christian Reshaping of a Jewish Model, 23-47.

${ }^{36}$ Merino Rodríguez, "Clemente de Alejandría, un filósofo cristiano", 810-811.

${ }^{37}$ Ibíd, 811.

${ }^{38}$ Löhr, "Christianity as Philosophy: Problems and Perspectives of an Ancient Intellectual Project", 160-188.

${ }^{39}$ Clemente de Alejandría, Stromata IV-V, Libro V, 1, 4. Fiskå Hägg, "Seeking the Face of God: Prayer and Knowledge in Clement of Alexandria", 131-142. "In Clement these two ways to the knowledge of God, through religious practice and theological reflection, are closely related. He seems to emphasize the mystical, supra-rational aspect in man's relationship with God more than had been common so far in the history of the church. In this he proved highly influential to the later, especially eastern, tradition. [...] Clement therefore distinguished between the unknown Father and the revealed Logos, the dynamis of God: God remains unknown, but the Son, Logos, or dynamis has revealed him to men" (ibid., 137). 
Por ello, la verdadera gnosis consiste en una aprehensión $(\dot{\varepsilon} \pi \iota \beta 0 \lambda \dot{\eta})$ y en un discernimiento ( $\delta\llcorner\dot{\prime} \lambda \eta \psi \iota \varsigma)$ de la verdad ${ }^{40}$. Si se trata de llegar a la verdad (Padre) por la verdad (Hijo), el conocimiento del Incognoscible ${ }^{41}$ requiere creer en el desconocido; por ello, la verdadera gnosis es contemplación plena ( $\theta \varepsilon o p i ́ a)$. En cuanto conocimiento intuitivo, la $\theta \varepsilon o p i ́ a$ se distingue del conocimiento discursivo, aunque están llamados a integrarse. En cuanto fundamento del conocimiento discursivo, el intuitivo puede darse solo, pues expresa el primado de la intuición inteligente sobre el discurso racional ${ }^{42}$.

Debido a ello, la fe es el oído del alma en cuanto el que ha creído comprende (escuchar como forma del comprender). Las referencias en que se sostiene Clemente son Mt 11,15 y Homero (Od., VI,185). De acuerdo con esta capacidad auditiva del alma y de la obediencia/desobediencia que de ella surge, se observa que la fe es susceptible de aumento o de disminución. Se diferencia de Basílides, a quien le atribuye afirmar que el elegido conoce a Dios por naturaleza $(\phi \dot{\sigma \varepsilon \varepsilon})^{43}$, pues el gnóstico considera que la inteligencia está próxima a la fe y a la creación de lo bueno, y entiende la fe como esencia, no como posibilidad.

Para el alejandrino, entender la fe como "posibilidad", es decir, como "facultad o libertad de hacer algo" (la referencia más significativa se encuentra en Platón, Gorg 461 e y Leg. 936 a) conlleva una idea de la fe como creación insuperable y también

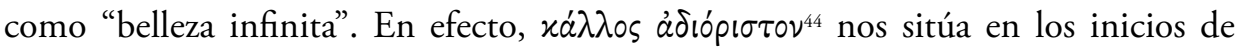
la teología especulativa, cuando intenta comprender la revelación bíblica en el contexto de la cultura helenística que, por ello, incluye de manera sistemática la filosofía y el mundo mítico-literario. Ká $\lambda \lambda$ os tiene aquí un significado de totalidad, a partir de una clara conciencia de la tradición bíblica y de la dimensión estética.

Entendemos que, en este contexto, Clemente se impone la tarea de afrontar una cuestión grave: ¿Puede la instancia estética helénica redimirse y ponerse al servicio de una comprensión más profunda del mensaje cristiano? ¿Es posible un diálogo entre lo ético-religioso y lo estético, entendiendo lo bello como la misma naturaleza originaria del mundo?

\footnotetext{
${ }^{40}$ Clemente de Alejandría, Stromata IV-V, Libro V, 1, 4. Términos de la epistemología epicúrea: Asmis, "Epicurean Epistemology", 260-294.

${ }^{41}$ Clemente de Alejandría, Stromata IV-V, Libro V, 82, 4.

${ }^{42}$ Sciacca, Loscuramento dell'intelligenza, 33; Ramelli, "The Divine as Inaccessible Object of Knowledge in Ancient Platonism: A Common Philosophical Pattern across Religious Traditions", 167-188.

${ }^{43}$ Clemente de Alejandría, Stromata IV-V, Libro V, 3, 1.

${ }^{44}$ Ibíd, 3, 2.
} 
Las dificultades de estas preguntas se encuentran más en nosotros que en el texto de Clemente; en crisis la noción de naturaleza ¿cómo presentar la raíz común de lo ético y de lo estético?

Lo que llamamos belleza está tan contaminado de irrealidad como la noción ilustrada de razón. Únicamente si somos capaces de descubrir el Logos que crea la belleza del cosmos, dejamos abierta la senda hacia la belleza originaria del amor de Dios. Para ajustar estas afirmaciones al momento histórico y cultural de Clemente debemos tener en cuenta que para él la Biblia es el documento más antiguo, y por ello, el más puro, que expresa la raíz de toda poesía.

"Aun cuando se quite la causa del investigar en todas las cuestiones, la fe se mantiene sólida...”45. Parece que esta referencia se encuentra en contradicción con lo que viene afirmando hasta aquí. Por nuestra parte, la entendemos en los siguientes términos: la fe no se define como postulado de la razón, pues no hay medida humana que resulte aceptable para lo divino; la razón no exige propiamente la gracia, sino que esta pone a la razón en tensión hacia Dios.

Si consideramos los elementos propios del acto de fe, se nos abre un camino que implica recíprocamente filosofía y teología, y luego mito y revelación. Si bien la fe se mantiene firme en el interior del creyente, en la medida en que cree, ella se identifica con el testimonio de Dios; de otro modo ¿cómo podría resultar concluyente una demostración que no nos conduzca a los umbrales de Dios? Si la vida ha comenzado, de algún modo, en la gracia, la fe es ya una cierta visión del ser de Dios: ella sostiene toda criatura, en cuanto establece los modos como Dios nos sale al encuentro en la percepción sensible y en el pensamiento, porque la profundidad de Dios no consiste en aseveraciones verbales, sino en la unidad del Hijo que da testimonio del Padre.

"Así, pues, afirmamos que no conviene que la fe progrese ociosa y sola, sino con

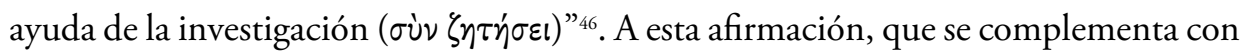
la cita anterior y la dimensiona, Clemente la considera en términos de "perspicacia del alma” ${ }^{47}$, es decir, la actitud más decisiva que toma el creyente que recrea espiritualmente su fe: una preocupación esencial por circunscribir la divinidad de Dios; calibrar la relación entre estos parámetros requiere de investigación ${ }^{48}$. Tal conocimiento ordena

\footnotetext{
${ }^{45}$ Ibíd., 2, 4.

${ }^{46}$ Ibíd, 11, 1.

${ }^{47}$ Ibíd, 11, 1; Remes, Neoplatonism, 5-6.

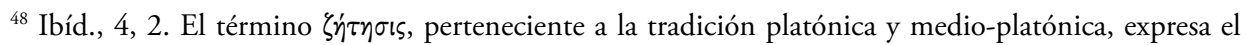
conocimiento científico por oposición al vulgar, tal como lo hallamos en Platón (Crat. 406 a; Tim. 47 a; Rep. 336 с y 368 c; Phaed. 66 d); Remes, Neoplatonism, 137-176.
} 
la actitud de la fe frente al Absoluto: la autoridad del revelarse de Dios radica en aquello que en semántica latina se denomina intellectus fidei o reconocimiento de que los actos culturales forman parte de las decisiones providenciales de Dios.

En este sentido, Clemente considera que los textos griegos precristianos pueden "decir algo": el ser no es un dato, sino expresión de la objetividad de todo ente; por ello, el acto filosófico significa para el hombre una justificación, en la que pone en juego toda su existencia; únicamente desde la intimidad de esta decisión es posible alcanzar la luz de Dios que sostiene el ser. Así, el acto filosófico conduce a las puertas de la fe y abre a su aceptación o rechazo (la posibilidad más elevada de libertad se da como tal en el ser).

El paso siguiente, si tiene lugar, lleva a su plenitud el discernimiento filosófico, en cuanto significa el encuentro con el ser en términos de amor; la angustia por el propio destino se transforma en abandono que no se preocupa de su destino. En otras palabras, se trata de la razón que piensa a la luz de la fe: una fuerza purificadora que ayuda a la razón a ser ella misma, en cuanto la refiere, con palabras de Romano Guardini, a las realidades espirituales y personales ${ }^{49}$.

¿Cómo se da entonces el conocimiento de Dios? En principio, se puede plantear según los diversos niveles de la comprensión humana. El primero, el más universal y menos diáfano, pero accesible a todos, se insinúa en el hombre en el momento de la creación. Por ello, señala Clemente, en Stromata VII, 8, 2, que los paganos pudieron alcanzar un conocimiento oscuro de Dios. Se trata ciertamente de un conocimiento ( $\pi \rho \dot{ } \lambda_{\eta} \psi \downarrow \iota$, en el vocabulario del alejandrino) sumamente imperfecto, pero real.

El segundo se denomina $\varkappa a \tau^{\prime}$ है $\mu \phi a \sigma \nu$ e implica la imagen espejada, es decir, el conocimiento que se alcanza en el alma entendida como imagen y, entonces, también como espejo de Dios; el modo de conocerlo implica el camino propiamente filosófico, que se entiende como don de Dios. Esta doctrina, que tendrá tan amplias repercusiones en la patrística y en la escolástica, aparece por vez primera en Clemente ${ }^{50}$.

\section{Stromata $V, 89,1-100,4$}

En el marco de la noción del "plagio griego" ${ }^{51}$ a la revelación dada a Moisés, Clemente se aplica al estudio de la naturaleza divina y comienza por retomar la enseñanza estoica sobre el tema: Dios es cuerpo y espíritu por esencia, principio que se aplica también

\footnotetext{
${ }^{49}$ Guardini, “Spirito vivente”, 93-117.

${ }^{50}$ Merino Rodríguez, “Clemente de Alejandría, un filósofo cristiano”, 817-818.

${ }^{51}$ Clemente de Alejandría, Stromata IV-V, Libro V, 14, 89. 1: “...H encontramos expresada la misma idea (Daniélou, Mensaje evangélico y cultura helenistica, 78-80).
} 
al alma. El alejandrino señala que el saber transmitido por los estoicos se encuentra literalmente en las Escrituras ${ }^{52}$ aunque, a diferencia de su metodología usual, se detiene en las diferencias que ambas cosmovisiones plantean, a partir de lo que parece una simple continuidad: en la inmanencia absoluta de la física estoica, el principio divino comunica su esencia penetrando todas las cosas, en la medida en que desciende a los estratos inferiores del cosmos, hasta su completa identificación. “... ellos (los estoicos) afirman que Dios penetra a través de toda la esencia; nosotros, en cambio, decimos que él es el único hacedor, y hacedor por el Logos" ${ }^{33}$.

Se impone, en este contexto, una reflexión sobre la materia, pues sin ella es imposible pensar aquel principio de compenetración, y en eso coinciden platónicos, aristotélicos y estoicos; en este marco, Platón es, sin lugar a duda, el que da el paso más audaz, pues denomina "no-ser" a la materia ${ }^{54}$; por ello, Clemente considera que Platón está en posesión de un conocimiento más misterioso ${ }^{55}$, que lo lleva a dudar acerca de si existe un principio o principios, tal como leemos en Timeo 48 c.

El giro de la argumentación clementina toma una dirección inusual, pues considera que el resto de las corrientes filosóficas se encuentran en el error, porque son producto de interpretaciones desacertadas de las Escrituras; así la idea epicúrea de "introducción furtiva o repentina" ${ }^{6}$ resulta de la incomprensión de Qo 12,8-14: “...vanidad de vanidades, todo vanidad”.

En el contexto de esta filosofía, tal como nos la presenta el poeta-filósofo romano Lucrecio, leemos la máxima "nada surge de la nada" 57 , negando de este modo y de manera explícita todo tipo de acción providencial por su teoría de los átomos. Clemente considera la comprensión epicúrea del contenido del Qohélet o Eclesiastés en términos de ausencia de un orden preestablecido y conocido por la providencia. Algo similar ocurre con Aristóteles, pues entiende que la acción de la providencia tiene su límite en la luna; aquí Clemente considera que hay una comprensión errada del Sal 35,658, aunque con un argumento en favor de Aristóteles: los misterios proféticos se revelaron únicamente con la venida de Cristo ${ }^{59}$.

${ }^{52}$ Clemente de Alejandría, Stromata IV-V, Libro V, 14, 89. 2.

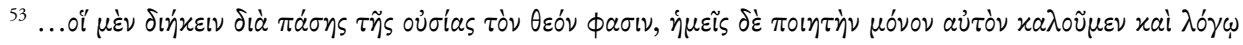
$\pi \circ \imath \eta^{\prime} \nu$ (ibíd.).

${ }^{54}$ Parm. 160 c - 162 a; Sof. 237 a- 254e; 225 a -259 d.; el giro es $\mu \grave{\eta}$ öv

${ }^{55}$ Clemente de Alejandría, Stromata IV-V, Libro V, 14, 89. 1. 7.

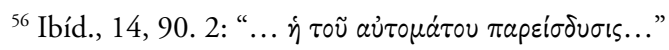

${ }^{57}$ De rerum natura I, 155-160.

58 "Señor, tu misericordia está en el cielo y tu verdad llega hasta las nubes".

${ }^{59}$ Clemente de Alejandría, Stromata IV-V, Libro V, 14, 90. 3. 
En cuanto a los tópicos del castigo de las almas por el fuego, en referencia tal vez a la doctrina cristiana del Purgatorio, Clemente considera que los relatos mitológicos, como las reflexiones teóricas provienen de la "filosofía bárbara"; así interpreta $\operatorname{Rep} \mathrm{X}, 615$ e-616 a la luz del Sal 103,6 60: los varones salvajes que en el texto platónico aparecen cubiertos de fuego son ángeles, que Dios transforma en fuego abrasador.

Clemente considera que el castigo después de la muerte es un argumento en favor de la inmortalidad del alma; en efecto, si el castigo es una perturbación de las sensaciones, es evidente que hay vida de algún tipo. Del mismo modo, los ríos de la geografía infernal (Cocito, Aqueronte, Piriflegetonte) tienen explicación para Clemente únicamente a partir de la noción de Gehena ${ }^{61}$.

El planteamiento de la inmortalidad del alma conlleva la reflexión sobre el carácter creatural del cosmos, en la que coinciden las tradiciones helénica (más precisamente platónica) y mosaica, siempre bajo la noción de plagio o robo ${ }^{62}$; Clemente entiende la forma verbal $\gamma^{\prime} \hat{y}{ } v \varepsilon \nu^{63}$ desde una perspectiva creacionista como "fue creado" (el sujeto tácito es "mundo" o "cosmos") y sostiene esta idea con una segunda cita del Timeo (28 c): “... es trabajoso descubrir al creador ( $\pi \circ \eta \eta \dot{\eta} \nu)$ y padre de todo"; hace extensiva a los estoicos esta noción de mundo creado por Dios.

De la creación del mundo depende el tratamiento sobre el origen y la naturaleza humana, en cuanto al alma y al cuerpo. Clemente afirma que el conjunto de las tradiciones griega y judía distinguen dos órdenes del mundo, uno inteligible o paradigma y otro sensible o imagen, y por ello considera que la noción de unidad o Logos (el texto de referencia es Gn 1,1-2), que sustenta al mundo inteligible, contiene el cielo invisible, la tierra informe y la luz inteligible ${ }^{64}$.

"Hágase la luz" conlleva la estructura del mundo sensible: cielo sólido, tierra visible y luz; por ello, Clemente considera que allí encontramos el núcleo central de la filosofía platónica, pues el ateniense coloca las ideas de los seres vivos en el núcleo inteligible, que produce las formas sensibles. Esta estructura de pensamiento, en la que están incluidas ambas filosofías, se coordina mediante el adverbio eixót $\omega \varsigma$ ("de la misma manera", "igualmente"), pues establece el nexo del nivel cósmico con el

\footnotetext{
${ }^{60}$ Ibíd., 14, 90, 4-6.

${ }^{61}$ Ibíd., 14, 90, 5; Bierbaum, "Geschichte als Paidagogia Theou. Die Heilsgeschichtelehre des Klemens von Alexandrien", 254-257.

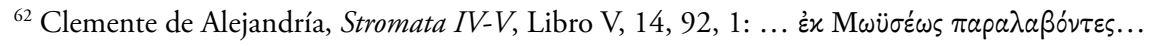

${ }^{63}$ Tim 28b, en Clemente de Alejandría, Stromata IV-V, Libro V, 14, 92, 3.

${ }^{64}$ Ibíd., 14, 93, 4.
} 
antropológico ${ }^{65}$; esto significa que en ambas tradiciones el ser humano fue formado de la tierra y el alma insuflada por Dios en el rostro y, consecuentemente, la hegemonía del alma sobre el cuerpo en Platón y, en sede bíblica, la comprensión de hombre como "imagen y semejanza" ${ }^{6}$ : el Logos es la imagen de Dios y la semejanza, la inteligencia humana, "imagen de una imagen" 67.

Si bien el fundamento de la semejanza descansa sobre un texto del Deuteronomio $(13,4)$, cuyo núcleo establece que aquella se alcanza siguiendo al Señor y cumpliendo sus mandamientos, Clemente introduce una oración adversativa que, al tiempo, amplía la perspectiva y deja conocer su pensamiento: “...pienso que todos los virtuosos son seguidores y servidores de Dios" ${ }^{\prime 6}$. El entramado de citas culmina en la idea de que "todo hombre bueno" ${ }^{69}$ sigue las huellas de Dios; en sede filosófica, la argumentación parte de los estoicos: llevar una vida conforme a la naturaleza ${ }^{70}$. Para Clemente, la progresiva semejanza del hombre con Dios, tal como la establece Platón, es el fundamento filosófico de la convicción cristiana de la progresiva transformación en el bien.

Con una cita de Leyes (IV,716), Clemente une las distintas líneas de su argumentación que había abierto en el diálogo de textos griegos con Gn 1,26; por ello, el modo de vida, que acrecienta la perfección del bien, procede de Dios, pues es la medida de las relaciones que puedan establecerse. Si buscar es salir al encuentro del Dios de la gloria, esto es tan válido en Tales de Mileto como en Hechos; en efecto, si Dios, "lo que no tiene ni principio ni fin", como cita Clemente a Tales ${ }^{71}$, está íntimamente vinculado al que es glorificado por los siglos de los siglos, entonces todo obrar a lo largo de la historia se consuma en él.

La correlación de textos que ponen en diálogo la asimilación platónica y la conversión cristiana culmina con la siguiente cita: "Mira, he puesto ante tus ojos el bien y el mal, la vida y la muerte. Elije la vida"72. "Vida", para Clemente, tiene diversos niveles de comprensión: en principio, la identificación entre vida y salvación; en correlación con lo anterior, vida expresa la elección del bien y de la belleza, la que se

\footnotetext{
${ }^{65}$ Ibíd., 14, 94, 2.

${ }^{66}$ Gn 1,26 en Clemente de Alejandría, Stromata IV-V, Libro V, 14, 94, 4.

${ }^{67}$ Ibíd., 14, 94, 5.

${ }^{68}$ Ibíd., 14, 94, 6.

${ }^{69}$ Ibíd., 14, 96, 1.

${ }^{70}$ Ibíd., 14, 95, 1.

${ }^{71}$ Ibíd., 14, 96, 4.

${ }^{72}$ Dt 30,15, en Clemente de Alejandría, Stromata IV-V, Libro V, 14, 97, 1.
} 
concreta en la búsqueda de ser "amigo de Dios", pues lo bueno y lo bello conducen a la verdad ${ }^{73}$. Clemente nos recuerda la enseñanza de Cristo, según la cual la ley y los profetas están contenidos en el mandato del $\mathrm{amor}^{74}$. Por ello, el alejandrino considera que Platón expresa también esta verdad: "Oh Pan y demás dioses, concededme ser hermoso en mi interior" 75 " $\mathrm{y}$ el que habla hermosamente es bello y bueno"76.

Que Clemente entienda, en términos platónicos, la virtud como búsqueda interior de belleza y de verdad significa colocar uno de los fundamentos de la teología cristiana naciente. Se trata de un punto especialmente importante en la argumentación de nuestro artículo, pues, a partir de esta correspondencia, se entiende que la puesta en diálogo de la cultura griega y la Biblia tiene una finalidad pedagógica. En efecto, como toda enseñanza proviene del único Maestro ${ }^{77}$, puede sostener esta verdad con una cita platónica: "Todos los que estáis en la ciudad sois hermanos"78.

En la misma cita se encuentra el texto en el que Platón incorpora, aunque modificándolo desde la raíz, la relación de impronta hesiódica entre la nobleza de los metales y las cualidades personales: en sus designios, Dios mezcló oro en los destinados a gobernar; plata entre los que colaboran con aquéllos; bronce y hierro para artesanos y labradores ${ }^{79}$. Clemente interpreta el pasaje en estos términos: el oro, que es puesto en conexión con el Espíritu Santo, refiere a los cristianos; la plata, a los judíos y el bronce, a los griegos ${ }^{80}$.

Clemente culmina con una delicada correlación de textos sobre la naturaleza humana, que sirve de fundamento a la relectura del pasaje platónico de los metales; las tradiciones, en efecto, coinciden en que el ser humano fue formado del polvo de la tierra: Homero dijo "convertíos en agua y en tierra"s1; e Isaías, "pisadlos como barro" 82; por último, la referencia de Calímaco a Prometeo: “...era aquel año, en que el pájaro y el que vive en el mar y el cuadrúpedo también emitían sonidos, como

\footnotetext{
${ }^{73}$ Ibíd., 14, 96, 5.

${ }^{74}$ Ibíd., 14, 97, 1.

${ }^{75}$ Phaed. 279 b, en Clemente de Alejandría, Stromata IV-V, Libro V, 14, 97, 2.

${ }^{76}$ Teet. 185e, en Clemente de Alejandría, Stromata IV-V, Libro V, 14, 97, 3.

77 Ibíd., 14, 98, 1.

${ }^{78}$ Resp. 415a, en Clemente de Alejandría, Stromata $I V$-V, Libro V, 14, 98, 1.

${ }^{79}$ Resp. 415a; 479, en Clemente de Alejandría, Stromata IV-V, Libro V, 14, 98, 1.

${ }^{80}$ Ibíd., 14, 99, 1.

${ }^{81}$ Il. VII, 99, en Clemente de Alejandría, Stromata IV-V, Libro V, 14, 99, 4.

${ }^{82}$ Is 10,6, en Clemente de Alejandría, Stromata IV-V, Libro V, 14, 99, 4.
} 
el barro de Prometeo" ${ }^{83}$. En el mismo sentido, el alejandrino recuerda la orden de Zeus a Hefesto: "Ordenó al ilustre Hefesto que lo más pronto posible mezclara tierra con agua y le infundiera voz humana e inteligencia" ${ }^{84}$.

De este modo, un teólogo como Clemente encara la presencia de Dios en la cultura pagana, pues en esta fundamentación se juega también la comprensión de por qué el Padre entregó al mundo a su Hijo y por qué el Espíritu Santo da la capacidad de comprender lo que es propio de Dios, es decir, descubrir la revelación y su autenticidad por medio de los cambios históricos y las transformaciones culturales ${ }^{85}$.

Tal lectura representa el aporte de Clemente a la teología del cristianismo primitivo y expresa dos perspectivas íntimamente correlacionadas: por una parte, la teología natural hace de la criatura una alusión a Dios, pues es su vestigio, si aceptamos que todo proviene de él; por otra, la vertiente estética de la experiencia cristiana, tal como la representa Clemente, en cuanto la experiencia religiosa se extiende a todo el orden de la salvación.

Este modo de universalizar la experiencia religiosa como trasiego cultural es un aporte del alejandrino, cuya mentalidad helénica se encamina a manifestar no solo cómo es estar cerca o lejos de Dios, sino también a comprender la historia cultural de modo providencial, pues en él resulta correlativa la finitud de la forma individual y su referencia al ser en sentido absoluto ${ }^{86}$.

\section{Conclusiones}

En la primera parte de nuestro trabajo hemos procurado presentar la proximidad y la distancia de Clemente respecto de la cultura de su época; que los maestros hasta el siglo IV fueran invariablemente paganos le permitió adquirir sólidos fundamentos literarios y filosóficos, así como haber frecuentado la escuela de Panteno, en Alejandría, le permitió consolidar su formación cristiana.

Por eso hay para él una correlación natural entre la experiencia arquetípica del Antiguo Testamento y la belleza intramundana de la cultura helénica. Sobre esto último, y como su sustrato, hemos presentado la noción clementina de una tradición primordial, originada en Egipto, de cuyo detritus resulta expresión el mito griego. Platón fundamenta su pensamiento en el desafío de interpretar con la mayor

\footnotetext{
${ }^{83}$ Frag, 192, 1-3, en Clemente de Alejandría, Stromata IV-V, Libro V, 14, 100, 1.

${ }^{84}$ Hes. Erga, 60-62, en Clemente de Alejandría, Stromata IV-V, Libro V, 14, 100, 3.

${ }^{85}$ Von Balthasar, Gloria. Una estética religiosa, 1, 263-290

${ }^{86}$ Escandell, "La inclinación natural a conocer la verdad acerca de Dios”, 373-386, esp. 375.
} 
fidelidad y agudeza aquella cultura primordial y de apropiarse de sus rasgos esenciales, como podemos seguir en El banquete (189 c).

A partir de aquí consideramos las características de la alegoría como un modo determinado de escribir y de leer, que se encuentra profundamente arraigado en la cultura clásica y que, si bien estimamos que pasa a Clemente por vía platónica, con las tensiones que se encuentran ya en el maestro ateniense, se constituye en uno de los medios para la comprensión de Dios, a partir de la herencia greco-latina. En este sentido, consideramos que hemos presentado la convicción de Clemente de Alejandría, que considera propia del cristianismo toda apertura de Dios al mundo, a partir de la lectura cristológica que realiza del legado humano.

Clemente retoma el tratamiento del tema de la fe, entendida como la verdadera gnosis, es decir, como discernimiento de la verdad. Si se trata de llegar al Padre por el Hijo, lo cual requiere creer en el desconocido, el alejandrino entiende la fe

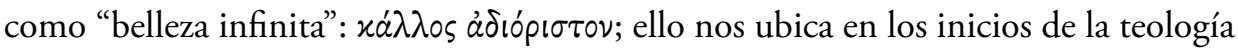
especulativa, que intenta comprender la revelación bíblica y que por ello incluye de manera sistemática la filosofía y el mundo mítico-literario.

En el contexto de Ká $\lambda \lambda$ os, Clemente se impone la pregunta: ¿Es posible un diálogo entre lo ético-religioso y lo estético, entendiendo lo bello como la naturaleza originaria del mundo? Si consideramos los elementos propios del acto de fe en términos de percepción teológica, se abre un camino que implica recíprocamente filosofía y teología y luego mito y revelación.

Si el ser manifiesta la objetividad del ente, el acto filosófico significa para el hombre poner en juego toda su existencia; únicamente desde la intimidad de esta decisión es posible alcanzar el conocimiento de Dios que sostiene el ser. En un conocimiento de esta naturaleza están implicados distintos grados de comprensión: desde el más universal y más difuso, pero común a todos, que se despliega a partir del instante de la creación, hasta lo que Clemente denomina $x a \tau^{\prime}$ ê $\mu \phi a \sigma \iota \nu$, es decir, la imagen espejada o conocimiento que se alcanza en el alma entendida como reflejo en Dios; es el modo de conocer de quienes hacen un recto uso de la razón, pues expresa el camino propiamente filosófico y se entiende a sí mismo como un don divino.

La revelación ha dado a la historia un nuevo significado que requiere de la comprensión metafísica, pues Cristo, al asumir la forma humana, ha incorporado la humanidad a la historia, en un sentido completamente nuevo. La peculiar lectura clementina de la cultura clásica permitió sostener intelectualmente la experiencia de la fe y ofrecer una justificación desde el punto de vista teológico. Los condicionamientos hermenéuticos que hemos señalado no empecen el esfuerzo por entender la fe como un encuentro del hombre con Dios. 
Clemente comienza a plantearse tanto la evidencia de lo creído cuanto el sustento providencial de la cultura pagana. Esta perspectiva teológica se sostiene en una reflexión sobre la tradición de pertenencia, con la intención dialógica de hallar el principio de unidad en modos culturales complementarios.

En la perspectiva de Stromata eso es posible porque, desde el origen, se manifiesta artísticamente un interpretar al hombre en su relación con la divinidad: el saber mítico y filosófico de los griegos sobre Dios había sido, por ello mismo, también teológico, en cuanto resultaba manifiesto en el cosmos. Así comprendemos, con Clemente de Alejandría, la problemática grandeza de la teología: ningún recurso intelectual le es ajeno al momento de especular acerca del misterio de la fe.

Esta consideración nos abre una puerta hacia lo esencial: entrar en posesión de una herencia cultural implica que esta debe ser depurada en cuanto instrumento de comprensión; así la relectura platónica de la correlación entre la pureza de los metales y las disposiciones humanas es indicativa del camino de la teología de Clemente, pues el contexto cósmico y humano resulta indicativo del misterio de la fe. Esta dirección siempre ha estado en revisión y en crisis, porque la persona de Cristo está siempre en riesgo de quedar oculta, desde la perspectiva de nuestro entendimiento, por la necesaria referencia cósmico-mítica.

Si tenemos en cuenta lo que hasta aquí hemos desarrollado, consideramos que Clemente integra la herencia clásica como un instrumento para la comprensión de Dios, a partir de la lectura cristológica que realiza para comprender el legado de la cultura humana, pues "todo proviene del único Maestro".

\section{Referencias}

Asmis, Elizabeth. "Epicurean Epistemology". En The Cambridge History of Hellenistic Philosophy, editado por K. Algra, J. Mansfeld y M. Schofield, 260-294, Cambridge: Cambridge University Press, 1999.

Bailly, Anatole. Dictionnaire Grec-Français. Paris: Hachette, 1963.

Bierbaum, W. "Geschichte als Paidagogia Theou. Die Heilsgeschichtelehre des Klemens von Alexandrien". Münchener Theologische Zeitschrift 5 (1954): 254-257.

Boys-Stones, George R. Post-Hellenistic Philosophy: A Study of its Development from the Stoics to Origen. Oxford: Oxford University Press, 2001.

Calabrese, Claudio. "Literatura y teología en el Libro X de La ciudad de Dios". Classica et christiana 12 (2017): 69-88. 
Clément d'Alexandrie, Les Stromates, Stromate V. Tome 1. Introduction, Texte Critique et Index par A. le Boulluec. Traduction par P. Voulet; SChr. 298. Paris: Du Cerf, 1981.

Clemente de Alejandría. Stromata I. Introducción, traducción y notas de Marcelo Merino Rodríguez. Madrid-México-Buenos Aires: Ciudad Nueva, 1996. . Stromata $I V-V$. Introducción, traducción y notas de Marcelo Merino Rodríguez. Madrid-México-Buenos Aires: Ciudad Nueva, 2003.

Daniélou, Jean. Mensaje evangélico y cultura helenistica. Madrid: Cristiandad, 2002.

Dawson, David. Allegorical Readers and Cultural Revision in Ancient Alexandria. Berkeley-Los Angeles-Oxford: University of California Press, 1992.

Diels, Hermann, y Walther Kranz. Die Fragmente der Vorsokratiker. Berlin: Weidmannsche Verlagsbuchhandlung, 1960.

Duchemin, Jacqueline. "Le mythe de Prométhée à travers les âges". Bulletin de l'Association Guillaume Budé 3 (1952): 39-72.

Escandell, José J. “La inclinación natural a conocer la verdad acerca de Dios”. Espíritu LXVII/156 (2018): 373-386.

Fiska Hägg, Henny. Clement of Alexandria and the Beginnings of Christian Apophanticism. Oxford: Oxford University Press, 2006.

. "Seeking the Face of God: Prayer and Knowledge in Clement of Alexandria". En The Seventh Book of the Stromateis. Proceedings of the Colloquium on Clement of Alexandria (Olomouc, October 21-23, 2010), editado por Matyáš Havrda, Vít Hušek y Jana Plátová, 131-142. Leiden-New York; Brill, 2012.

Guardini, Romano. "Spirito vivente". En Natura, cultura, cristianesimo: saggi filosofici, por R. Guardini, 93-117. Brescia: Morcelliana, 1983.

Havrda, Matyáś. "Some Observations on Clement of Alexandria, Stromata, Book Five". Vigiliae christianae 64 (2010): 1-30.

Herren, Michael. The Anatomy of Myth. The Art of Interpretation from the Presocratics to the Church Fathers. Oxford: Oxford University Press, 2017.

Hesiod. Theogony. Oxford-New York: Oxford University Press, 1988.

Junco, Ethel. "La sabiduría moral: entre Eurípides y Sócrates". Classica et christiana 13 (2018): 45-61.

Kerényi, Karl. Imágenes primigenias de la religión griega. IV. Prometeo. Interpretación griega de la existencia humana. México: Sexto Piso, 2011. 
Klibengajtis, Tomasz. "Die Wahrheitsbezeichnungen des Clemens von Alexandrien in ihrem philosophischen und theologischen Kontext". Vigiliae Christianae 58/ 3 (2004): 316-331.

Lamberton, Robert. Homer the Theologian: Neoplatonist Allegorical Reading and the Growth of the Epic Tradition. Berkeley-Los Angeles-London: University of California Press, 1986.

Löhr, Winrich. "Christianity as Philosophy: Problems and Perspectives of an Ancient Intellectual Project”. Vigiliae christianae 64/ 2 (2010): 160-188.

Marrou, Henry-I. Historia de la educación en la Antigüedad. Madrid: Akal, 1985.

Merino Rodríguez, Marcelo. "Clemente de Alejandría, un filósofo cristiano”. Scripta theologica 40/3 (2008): 803-837.

Moreschini, Claudio. Storia del pensiero cristiano tardo-Antico. Milano: Bompiani, 2013.

Osborne, Catherine. "Clement of Alexandria". En The Cambridge History of Philosophy in Late Antiquity. Vol. I, editado por L. P. Gerson, 270-282. Cambridge: Cambridge University Press, 2010.

Osborn, Eric. The Emergence of Christian Theology. Cambridge: Cambridge University Press, 1993.

Pfeiffer, Rudolph. History of Classical Scholarship from the Beginnings to the End of the Hellenistic Age. Oxford: Clarendon Press, 1968.

Philon d'Alexandrie. De congressu eruditionis gratia. Introduction, traduction et notes par M. Alexandre. Paris: Du Cerf, 1967.

Ramelli, Ilaria. "The Divine as Inaccessible Object of Knowledge in Ancient Platonism: A Common Philosophical Pattern across Religious Traditions". Journal of the History of Ideas 75/2 (2014): 167-188. . “Origen and the Platonic Tradition”. Religions (2017): 6-8. https://doi. org/10.3390/rel8020021.

Remes, P. Neoplatonism. Stocksfield: Acumen, 2008.

Ruíz Aldaz, Juan I. El concepto de Dios en la teología del siglo II. Pamplona: Eunsa, 2006.

Sciacca, Michelle. L'oscuramento dell'intelligenza. Milano: Marzorati, 1970. 
Setaioli, Aldo. "Interpretazioni stoiche ed epicuree in Servio e la tradizione dell'esegesi filosofica del mito e dei poeti a Roma (Comuto, Seneca, Filodemo)". International Journal of the Classical Tradition 11/1 (2004): 3-46.

Snell, Bruno. Die Entdeckung des Geistes. Studien zur Entstehung des europäischen Denkens bei den Griechen. Göttingen: Vandenhoeck y Ruprecht GmbH \& Co., 2010.

Solano Pinzón, Orlando. "Gregorio de Nisa y el ejercicio de inculturación de la teología”. Theologica Xaveriana 184 (2017): 509-532. Disponible en: https:// doi.org/10.11144/javeriana.tx67-184.gneit

Stefaniw, Blossom. "Allegorical Exegesis in Late Antique Alexandria". Revue de l'histoire des religions 224/2. Divination et révélation dans les mondes grec et romain (2007): 231-251.

Struck. P. T. Birth of the Symbol. Ancient Readers at the Limits of Their Texts. Princeton (NJ)-Oxford: Princeton University Press, 2000.

Trousson, Raymond. Le thème de Prométhée dans la littérature européenne. Genève: Libraire Droz, 2001.

Van Den Hoek, Annewies. Clement of Alexandria and his Use of Philo in the "Stromateis". An Early Christian Reshaping of a Jewish Model. Leiden-New York: Brill, 1988.

Von Balthasar, Hans Urs. Gloria. Una estética religiosa. Vol. 1. Madrid: Encuentro, 1985. 